\title{
The Influence of Growth Temperature on the Properties of AlN Films Grown by Atomic Layer Deposition
}

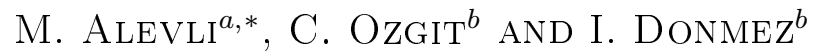 \\ ${ }^{a}$ Physics Department, Faculty of Arts and Sciences, Marmara University, Istanbul 34722, Turkey \\ ${ }^{b}$ UNAM — Institute of Materials Science and Nanotechnology, Bilkent University, 06800 Ankara, Turkey \\ In this work, we explored the influence of the low growth temperatures on the structural and optical properties \\ of AlN films grown by plasma enhanced atomic layer deposition using trimethylaluminum and ammonia $\left(\mathrm{NH}_{3}\right)$ \\ plasma. Structural and optical results show that AlN films grown by self-limited plasma enhanced atomic layer \\ deposition are polycrystalline at temperatures as low as $100^{\circ} \mathrm{C}$.
}

PACS: 81.15.Gh, 78.66.Fd, 78.55.Et

\section{Introduction}

Excellent physical and optical properties of AlN films such as high melting temperature, high thermal conductivity at room temperature, good chemical stability, wide band gap $[1,2]$ make AlN very promising for several applications such as UV-visible detectors and emitters, optoelectronic displays, and GaAs and silicon carbide passivation $[2,3]$. Furthermore, AlN is a suitable candidate for the fabrication of $\mathrm{Al}_{x} \mathrm{Ga}_{y} \mathrm{In}_{1-x-y} \mathrm{~N}$ [3] based electronic and optical device applications. AlN thin films have been grown by using several growth techniques under different growth conditions such as temperature, pressure, precursors, etc. While high-temperature (typically above $1100^{\circ} \mathrm{C}$ ) grown epitaxial AlN films are used in active electronic and optoelectronic device layers, polycrystalline and amorphous AlN films grown at CMOS-compatible temperatures (lower than $300^{\circ} \mathrm{C}$ ) are widely used as dielectric and passivation layers for microelectronic devices [4].

To utilize the full potential of the group III-nitride material system for the mature CMOS technology requires the growth of group III-nitride alloys and heterostructures in the temperature range below $300^{\circ} \mathrm{C}$. To overcome the presently encountered limitations for low growth temperatures, plasma enhanced atomic layer deposition (PEALD) of AlN is a promising growth technique which not only reduces the film growth temperature, but also satisfies critical conformality and sub-monolayer thickness control as well $[5,6]$. Although the growth of AlN films at different low growth temperatures $\left(100-500^{\circ} \mathrm{C}\right)$ has been studied by several groups based on PEALD growth method [7-9], the properties of crys-

\footnotetext{
* corresponding author; e-mail: mustafaalevli@marmara.edu.tr
}

talline AlN films grown with a typical sequential self limiting recipe have not been studied previously. Initially, the self limiting window $\left(100^{\circ} \mathrm{C}<T_{\text {growth }}<200^{\circ} \mathrm{C}\right)$ for AlN films was obtained by precisely adjusting the deposition temperature, reactant dose and length of the precursor pulses, in which each reaction step is saturative. In this ideal case, chemisorptions of each reactant occur on the surface of the growing film, overdosing precursor and increasing the growth temperature does not affect the growth rate and one layer of the AlN material was produced [5]. In the following, the growth temperature was increased up to $500{ }^{\circ} \mathrm{C}$ in order to investigate the properties of AlN films in the temperature dependent window $\left(230^{\circ} \mathrm{C}<T_{\text {growth }}\right)$. Deposition rates of AlN films at different growth temperatures are given in Fig. 1.

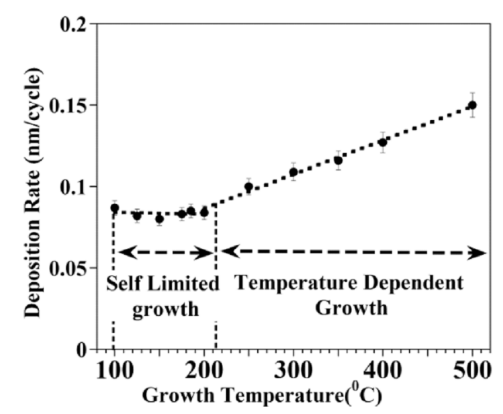

Fig. 1. Growth rate as a function of temperature.

\section{Experiment}

Aluminum nitride films were grown in a Cambridge Nanotech Fiji F200 remotely placed rf-plasma ALD reactor with a base pressure of 0.2 Torr. Pre-cleaned Si (100) and quartz substrates were used throughout the 
experiments. trimethylaluminum (TMA) and $\mathrm{NH}_{3}$ radicals were used as $\mathrm{Al}$ and $\mathrm{N}$ source, respectively, while $\mathrm{Ar}$ was used as the carrier/purging gas. A set of experiments was performed to identify the self-limiting ALD window in temperature range of $100-500{ }^{\circ} \mathrm{C}$ that produced self-limiting growth. One cycle for depositing AlN films consisted of the following parameters. TMA was pulsed for $0.1 \mathrm{~s}, 50 \mathrm{sccm}$ of $\mathrm{NH}_{3}$ plasma was exposed for $40 \mathrm{~s}$ with $200 \mathrm{sccm}$ Ar carrier, $10 \mathrm{~s}$ purge times were inserted after the TMA and $\mathrm{NH}_{3}$ steps which eliminated any possible gas-phase reactions. Plasma power was set to $300 \mathrm{~W}$. To investigate the effect of the growth temperature on the AlN film properties $\approx 100 \mathrm{~nm}$ thick AlN layers were deposited at $100,185,400$, and $500^{\circ} \mathrm{C}$.

The grazing incidence X-ray diffraction (GIXRD) and transmission electron microscopy (TEM) of all AlN films showed the prevalence of a highly polycrystalline hexagonal AlN structure. AlN films retain their crystalline structure upon decreasing growth temperature down to $100^{\circ} \mathrm{C}$ according to the GIXRD results. The structural properties and chemical composition of AlN films were characterized by X-ray photoelectron spectroscopy (XPS). XPS measurements were carried out at Thermo Scientific K-Alpha spectrometer equipped with monochromatized $\mathrm{Al} K_{\alpha}$ X-ray source. Film thickness and refractive index measurements were performed using a J.A. Woollam spectroscopic ellipsometer with a xenon light source. Surface morphology was characterized by atomic force microscopy (AFM) using Asylum Research, MFP-3D in contact mode. Room temperature transmission measurements were performed with a UV-visible-near infrared spectrometer, which consists of a built-in phase-sensitive detection and signal processing for the appropriate wavelength regions.

\section{Results and discussion}

We analyzed the elemental composition of AlN films using XPS. Figure $2 \mathrm{a}$ and $\mathrm{b}$ shows a series of $\mathrm{Al} 2 p$ and $\mathrm{N} 1 s$ spectra for different growth temperatures taken in the inner layers of AlN films, respectively. The Al $2 p$ and $\mathrm{N} 1 s$ binding energies of AlN are at $73.5 \pm 0.3 \mathrm{eV}$ and $396.4 \pm 0.3 \mathrm{eV}$, respectively [10]. Three distinct chemical states were observed for AlN films; the Al $2 p \# 1$ subpeak at $73.5 \pm 0.1 \mathrm{eV}, \mathrm{Al} 2 p \# 2$ at $72.4 \pm 0.1 \mathrm{eV}$ and $\mathrm{Al} 2 p \# 3$ at $74.5 \mathrm{eV}$. According to the Al $2 p$ XPS results, AlN was formed in all samples for all growth temperatures. An Al $2 p \# 3$ subpeak is obtained for AlN films grown at $100{ }^{\circ} \mathrm{C}$ and $500{ }^{\circ} \mathrm{C}$ which is correlated to $\mathrm{Al}-\mathrm{O}$ bound states [10]. Al $2 p \# 2$ subpeak is detected whose binding energy (BE) is clearly related to the $\mathrm{BE}$ of $\mathrm{Al}-\mathrm{Al}$ bond in AlN for intermediate growth temperatures [11]. The intensity of $\mathrm{Al} 2 p \# 3$ subpeak was more than the $\mathrm{Al} 2 p \# 1$ and $\mathrm{Al} 2 p \# 3$ subpeaks for AlN film grown at $100^{\circ} \mathrm{C}$. Furthermore, the $\mathrm{O} 1 s$ XPS analysis of AlN grown at $100{ }^{\circ} \mathrm{C}$ reveal a dominant subpeak at $531.5 \pm 0.1 \mathrm{eV}$. This is one of the possible explanations to the amorphous-like character of AlN sample grown at $100^{\circ} \mathrm{C}$ observed from the analysis of optical refractive index analysis. Additional information about the chemical structure of the AlN films is provided by the N $1 s$ spectra analysis. On the basis of the deconvolution of $\mathrm{N} 1 s$ XPS peak, the strongest peak at $396.3 \pm 0.3 \mathrm{eV}$ which was detected for all AlN films, is a typical $\mathrm{N}-\mathrm{Al}$ bond [10]. The almost-negligible peak at $398 \pm 0.3 \mathrm{eV}$ is $\mathrm{AlO}_{x} \mathrm{~N}_{y}$.

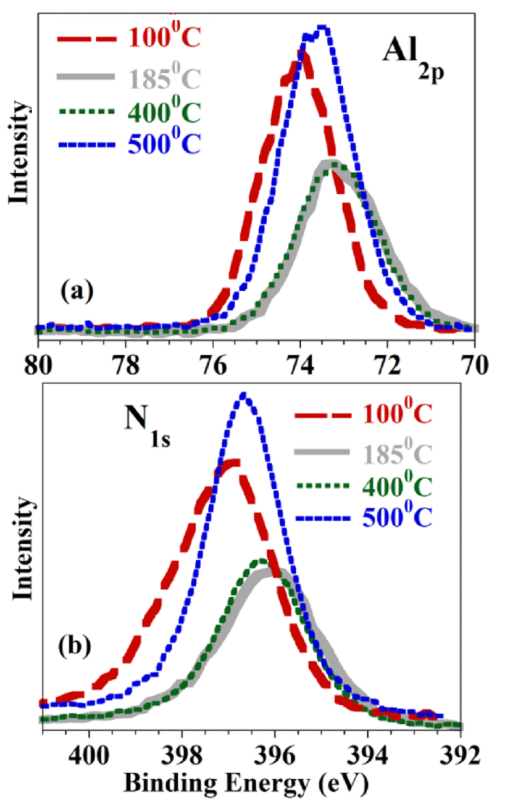

Fig. 2. XPS narrow scan of (a) $\mathrm{Al} 2 p$ and (b) $\mathrm{N} 1 s$ from AlN films deposited on Si (100) substrate with different growth temperatures of $100,185,400$ and $500{ }^{\circ} \mathrm{C}$ in two different growth regimes.

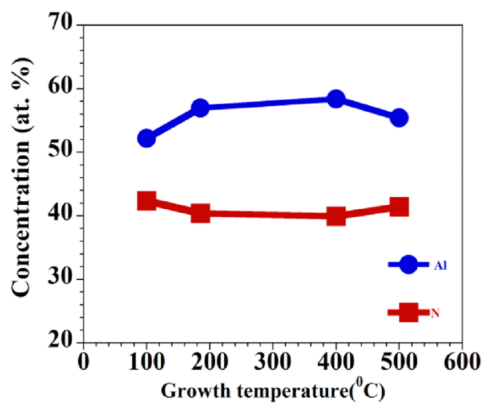

Fig. 3. Average atomic concentrations of AlN films as a function of the ALD growth temperature.

The effect of the growth temperature on the atomic concentrations is shown in Fig. 3. Al concentration increases until $400^{\circ} \mathrm{C}$ and it decreases with increasing temperature. $\mathrm{N}$ concentration remains constant up to $400^{\circ} \mathrm{C}$ and it starts to increase. Behaviors of those atomic concentrations might be totally related with the increase in the thermal cracking efficiency of both precursor species.

Figure 4 shows the influence of the growth temperature on the surface roughness and mean grain size of 


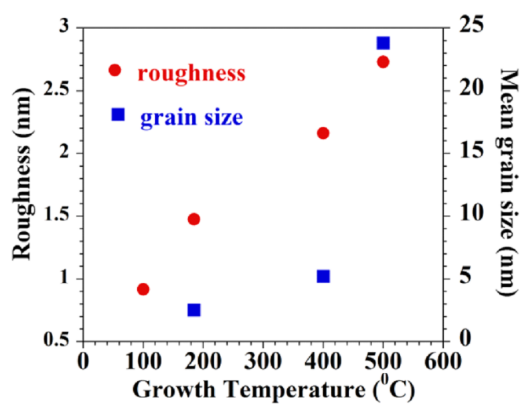

Fig. 4. Calculated mean grain size and roughness of the AlN films with varying growth temperature on Si (100).

AlN films. The mean grain size was deduced from the Gwyddion image analysis program. The AFM analysis revealed that the surfaces of AlN films become rougher and grain size become bigger as substrate temperature increases. Root mean square (rms) roughness of the film is relatively high for films grown at higher growth temperatures with 400 and $500^{\circ} \mathrm{C}\left(\mathrm{rms}=2.54 \mathrm{~nm}\left(400{ }^{\circ} \mathrm{C}\right)\right.$, $\left.\mathrm{rms}=2.16 \mathrm{~nm}\left(500^{\circ} \mathrm{C}\right)\right)$. The surface of the sample grown at low temperatures is smoother $(\mathrm{rms}=1.37 \mathrm{~nm}$ $\left.\left(185^{\circ} \mathrm{C}\right), \mathrm{rms}=0.93 \mathrm{~nm}\left(100^{\circ} \mathrm{C}\right)\right)$. In ALD growth, precursor self-decomposition occurs at higher temperatures which destroys the self-limiting growth control and leads to non-uniform films.

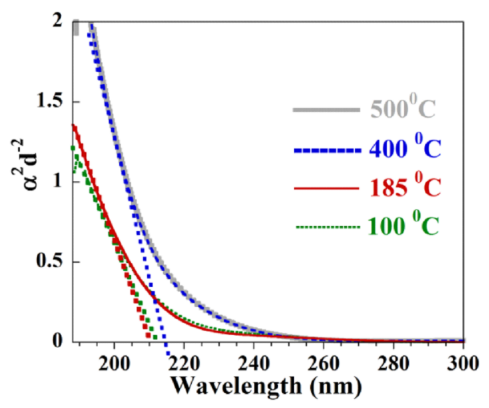

Fig. 5. The square of the product of the absorption coefficient of AlN films deposited on quartz substrates in three different growth regions.

The experimental absorption has been carried out and Fig. 5 shows a plot of the squared absorption coefficient, $\alpha^{2}$, as a function of wavelength in order to determine the energy of optical band edge for AlN films. The optical band edge can be determined by extrapolating the tangential line to the wavelength axis in the $\alpha^{2} d^{-2}$ vs. $\lambda$ plot. The optical band edge was observed at $5.82 \mathrm{eV}, 5.84 \mathrm{eV}$, and 5.78 for AlN films grown at $100^{\circ} \mathrm{C}, 185^{\circ} \mathrm{C}$, and 400 $500{ }^{\circ} \mathrm{C}$ samples, respectively. It can be seen from Fig. 5 that the optical band edge energy slightly decreases with the increase of the temperature. On the other hand, the optical band edges of AlN films grown at $100{ }^{\circ} \mathrm{C}$ behave not accordingly with growth temperature which might be due to the oxygen impurity related defects present in AlN films grown.

\section{Conclusions}

Both structural and optical properties showed that the hexagonal crystalline AlN thin films were obtained at growth temperatures as low as $100^{\circ} \mathrm{C}$ by PEALD method. The ultimate goal of this work is to present the properties of AlN films grown with self-limiting recipe as a function of growth temperature. Oxygen was detected as major impurity in the films. With increasing temperature metallic $\mathrm{Al}$ and $\mathrm{Al}-\mathrm{N}-\mathrm{O}$ bonding disappears and only $\mathrm{Al}-\mathrm{O}$ peak appears at the highest growth temperature. Despite the low deposition temperatures the films exhibited crystallinity. The increment in growth temperature and shift to decomposition limited regime cause a significant reduction in the near-band-edge absorption of the AlN films due to the decomposition of metal precursor and incorporation of oxygen related impurities.

\section{Acknowledgments}

This work was performed at UNAM supported by the State Planning Organization (DPT) of Turkey through the National Nanotechnology Research Center Project. M.A. acknowledges the financial support from TUBITAK (project No. 232.01-660/4835).

\section{References}

[1] E.F. McCullen, J.S. Thakur, Y.V. Danylyuk, G.W. Auner, L.W. Rosenberger, J. Appl. Phys. 103, 063504 (2008).

[2] Y. Lee, S. Kang, Thin Solid Films 446, 227 (2004).

[3] J. Khoshman, M.E. Kordesch, J. Non-Cryst. Solids 351, 3334 (2005).

[4] D. Riihela, M. Ritala, R. Matero, M. Leskela, J. Jokinen, P. Haussalo, Chem. Vap. Dep. 2, 277 (1996).

[5] H. Kim, J. Vac. Sci. Technol. A 21, 2231 (2003).

[6] M. Rittala, M. Leskela, in: Hand Book of Thin Film Materials, Ed. H.S. Nalwa, Academic Press, New York 2002, p. 103.

[7] K. Kim, N. Kwak, S. Lee, Electr. Mater. Lett. 5, 83 (2009).

[8] M. Bosund, T. Sajavaara, M. Laitinen, T. Huhtio, M. Putkonen, V.M. Airaksinen, H. Lipsanen, Appl. Surf. Sci. 257, 7827 (2011).

[9] X. Liu, S. Ramanathan, E. Lee, T.E. Seidel, Mater. Res. Soc. Symp. Proc. 811, 11 (2004).

[10] L. Rosenberger, R. Baird, E. McCullen, E. Auner, G. Shreve, Surf. Interface Anal. 40, 1254 (2008).

[11] S. Schoser, G. Brauchle, J. Forget, K. Kohlhof, T. Weber, J. Voigt, B. Rauschenbach, Surf. Coat. Technol. 103-104, 222 (1998). 